\title{
INFLUENCE OF COVID-19 LOCKDOWN ON AIR QUALITY
}

\author{
Gautam Gupta ${ }^{* 1}$ \\ ${ }^{*}$ Project Engineer, Wipro Limited, Chennai, Tamil Nadu, India \\ (Alumni, Mechatronics Engineer, Thapar Institute of Engineering and Technology, Patiala, Punjab, \\ India) \\ Bhavya Bhasin $^{* 2}$ \\ ${ }^{* 2}$ Masters of Clinical Psychology, Lovely Professional University, Phagwarah, Punjab, India \\ Sumedha Malhotra*3 \\ *3 Masters of Science (IT), Government College for Girls (Affiliated with PU), Ludhiana, Punjab, \\ India
}

Article DOI: https://doi.org/10.36713/epra5974

\begin{abstract}
In late 2019, a novel irresistible infection with human to human contagious transmission (COVID-19) was recognized in Wuhan, China, which has transformed into a worldwide pandemic. Nations everywhere in the world have executed a type of lockdown to hinder its contamination and moderate it. Lockdown because of COVID-19 effectively affects social and monetary fronts. In any case, this lockdown likewise has some constructive outcome on regular habitat. The study objective is to think about the adequacy of COVID-19 lockdown on the air contamination around the world. Because of pandemic, all avoidable activities around the globe were prohibited. Ongoing information delivered by NASA (National Aeronautics and Space Administration) and ESA (European Space Agency) demonstrates that the contamination level in certain nations has decreased up to $30 \%$. The nationwide halting of public transports and closure of major industrial units has resulted in obvious significant reductions in emissions of a variety of gases related to energy and transport. The decrease of air contamination was firmly connected with movement limitations during this pandemic and five air toxins i.e., SO2, PM2.5, PM10, NO2, and CO have likewise diminished.
\end{abstract}

KEYWORDS: Coronavirus, Curfew, Air Pollution, Pandemic, Shutdown.

\section{INTRODUCTION \\ COVID-19 has not just penetrated the hover} of the overall economy yet in addition halted transportation all through the world. These varieties have significantly had a positive effect on the natural quality. On January 30th, WHO announced an overall general wellbeing crisis. The plague transforms into pandemic and by end of March, half of the total populace was under some type of lockdown. COVID-19 has extreme negative effect on human wellbeing and world's economy; anyway it likewise brings about contamination decrease because of restricted social and monetary exercises.
Significant decreases in the AQI of $\mathrm{SO}_{2}, \mathrm{PM}_{2.5}, \mathrm{PM}_{10}$, $\mathrm{CO}$, and $\mathrm{NO}_{2}$ were observed during the lockdown period. Most nations have reported a type of lockdown to lessen the impacts of COVID-19 and cease the transmission of the novel coronavirus. (Anjum, 2020) Air is called contaminated when it shows hurtful groupings of a blend of particles and gases such as black carbon (soot), smoke, mold, pollen, methane $(\mathrm{CH} 4)$, and $\mathrm{CO}_{2}$. Particulate matter (PM), black carbon, ground-level ozone $\left(\mathrm{O}_{3}\right)$, nitrogen dioxide $\left(\mathrm{NO}_{2}\right)$, nitrous oxide $\left(\mathrm{N}_{2} \mathrm{O}\right)$, sulfur dioxide $\left(\mathrm{SO}_{2}\right)$ and carbon monoxide $(\mathrm{CO})$ are among the significant kinds of air contaminations. 


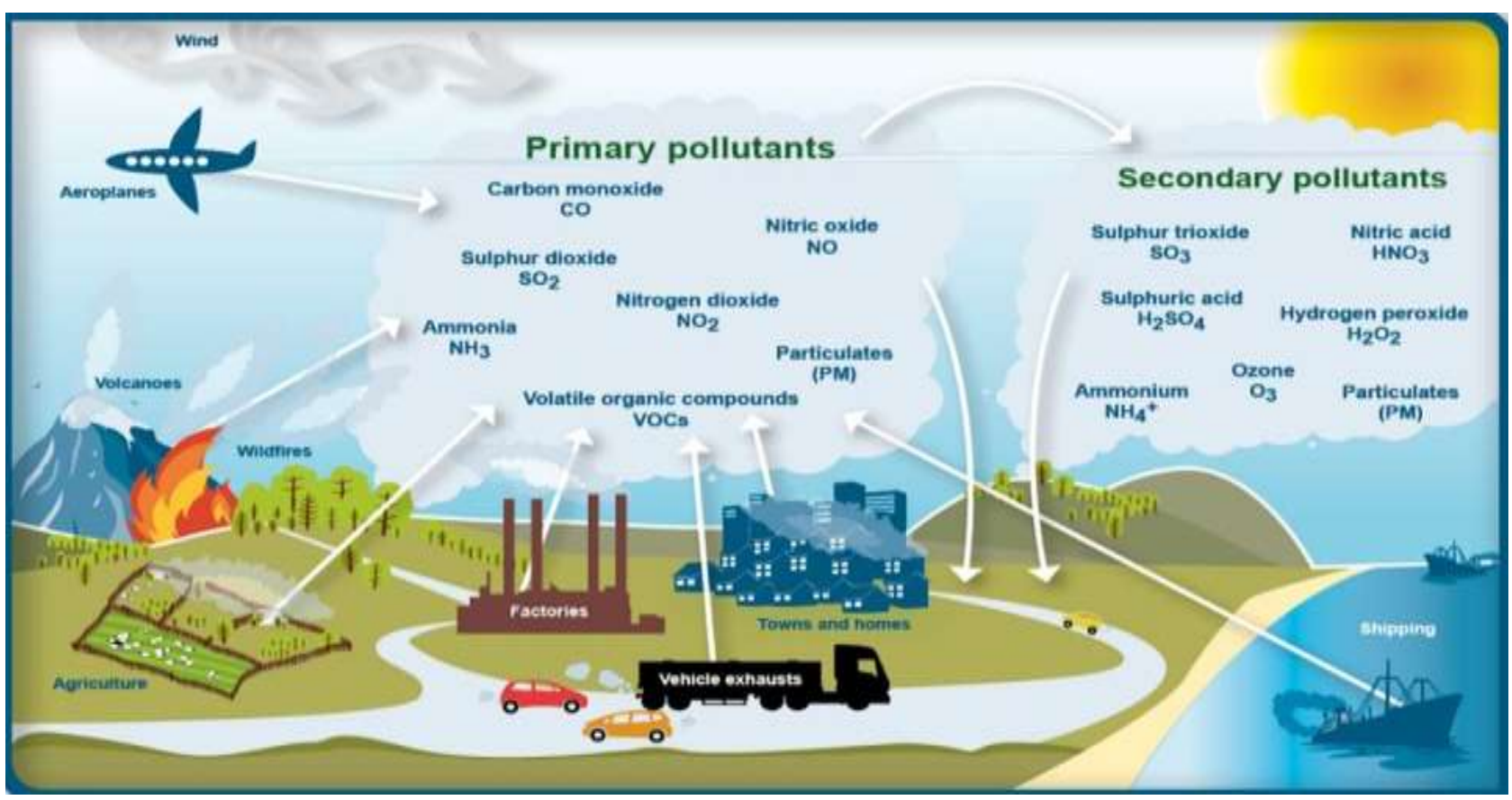

Figure 1 : Types and sources of major air pollutants (Helen 2020)

\section{LITERATURE REVIEW}

(Balasubramaniam et al., 2020) Assessed the impact of COVID-19 on air quality in USA, Italy, and France from March 2020 to May 2020. The climate change is mainly attributed due to air pollutants. In addition, this study reveals the significance of air quality and its relevance toward the spread of COVID-19. The emission level of $\mathrm{PM}_{10}, \quad \mathrm{PM}_{2.5}, \quad \mathrm{CO}$ and nitrous oxide showed significant reduction due to COVID-19 measures. (Gautam, 2020) This viewpoint gives proof of huge changes noticeable all-around nature of the Indian district during the public authority lockdown to decrease the impacts of COVID-19. As indicated by the outcomes and conversation, it very well may be viewed as that with the huge decrease of aerosol concentration during isolation, novel coronavirus may amazingly have diminished. (Huang \& Brown, 2020) This examination utilizes a plan to assess the effects of air contamination on COVID-19 disease in Germany by looking at topographical differences in air contamination. The outcomes show that a drawnout introduction to $\mathrm{NO}_{2}$ is altogether connected with the COVID-19 frequency rate in Germany. (Rossi et al., 2020) The point of this paper is to assess the effectiveness and limitations of these interventions, by analyzing the relationship between traffic flows and air quality. The used dataset contains concentrations of $\mathrm{NO}, \mathrm{NO}_{2}, \mathrm{NO}_{\mathrm{x}}$ and $\mathrm{PM}_{10}$, vehicle counts and meteorology, all collected during the COVID-19 lockdown in Italy.

(Coker et al., 2020) This paper exactly explores the ecologic relationship between long haul convergences of the region-level fine particulate issue $\left(\mathrm{PM}_{2.5}\right)$ and overabundance deaths in the first quarter of 2020 in quite a while of Northern Italy. (Venter et al., 2020) This paper has used an organization of $>10,000$ air quality stations dispersed more than 34 nations during lockdown dates up until 15 May 2020 to get lockdown related abnormalities for nitrogen dioxide, ozone, and particulate issue more modest than $2.5 \mu \mathrm{m}$ in measurement $\left(\mathrm{PM}_{2.5}\right)$. (Ghahremanloo et al., 2020) This examination uses satellite remote sensing to explore the effect of the coronavirus outbreak and the subsequent lockdown of public scenes on air contamination levels in East Asia. With enormous decreases in the convergences of $\mathrm{NO}_{2}$ during lockdown circumstances, we locate that huge expansion in ozone in East China. (Hoang \& Tran, 2020) This shows a huge nonlinear relationship between everyday temperature, $\mathrm{NO}_{2}$, $\mathrm{CO}$, and $\mathrm{SO}_{2}$ concentrations, and everyday COVID19 affirmed cases in Korea. (Son et al., 2020) This investigation inspected the effects of COVID-19 relief gauges on air contamination levels and the resulting decreases eternality for metropolitan regions in 10 US states and the District of Columbia. We found that $\mathrm{PM}_{2.5}$ focus during the relief time frame diminished for most states and the capital.

\section{IMPACT ACROSS WORLD}

Worldwide and neighborhood transportation has been decreased, which diminishes oil utilization and energy usage. Subsequently, government placed their nation on lockdown to hinder the spread of disease and simplicity trouble on wellbeing offices. Close down of the public vehicle, instructive establishments, organizations focuses, leaves, and 


\section{EPRA International Journal of Climate and Resource Economic Review}

Volume: 8 | Issue: 3 |December 2020 || SJIF Impact Factor (2020): 7.043 || Journal DOI: 10.36713/epra1213

other social association focuses to diminish the transmission of COVID-19. (Muhammad et al., 2020) Among numerous different areas, transport is the hardest hit area because of lockdown. Street and air transport came to end as individuals are not permitted or dither to travel. As indicated by the report, air travel dropped by $96 \%$ because of COVID-19, the least in 75 years.

Worldwide oil requests declined radically and costs cut down pointedly, as modern and transport areas came to stop around the world. (Fu et al., 2020) Lockdown because of COVID-19 diminished vehicle exercises which brings about less energy utilization and lower oil interest. These adjustments in vehicle exercises and oil requests apply a critical effect on ecological quality. The nationwide halting of public transports and closure of major industrial units has resulted in obvious significant reductions in emissions of a variety of gases related to energy and transport.

- Bangladesh

- Across country lockdown was forced on 26 March 2020, due to the COVID-19 pandemic. (Islam et al., 2020) Dissected satellite information for four distinctive air contaminations $\left(\mathrm{NO}_{2}, \mathrm{SO}_{2}, \mathrm{CO}\right.$ and $\mathrm{O}_{3}$ ) to evaluate the adjustments in the barometrical groupings of contaminations the nation over. Among the significant urban communities, Dhaka, Gazipur, Chattogram, and Narayanganj were discovered to be more impacted by the limited outflows. The average $\mathrm{SO}_{2}, \mathrm{NO}_{2}$ and $\mathrm{CO}$ concentrations were diminished by $43 \%, 40 \%$ and $5.3 \%$ respectively, while $\mathrm{O}_{3}$ were discovered to be expanded with $7 \%$.

- Canada

○ In March of 2020, many provinces in Canada proclaimed a State of Emergency (SOE) to lessen the spread of extreme intense respiratory condition coronavirus. (Adams, 2020) During the SOE in 2020 mean air contamination fixations across Ontario air monitor screens were lower than earlier years during that period (weeks 13-17) for $\mathrm{NO}_{2}, \mathrm{NO}_{\mathrm{X}}$ and $\mathrm{O}_{3}$; however, $\mathrm{PM}_{2.5}$ demonstrated average conditions. Toxins with source profiles that are overwhelmed by transportation emanations demonstrated clear decreases, which included both $\mathrm{NO}_{2}$ and $\mathrm{NO}_{\mathrm{X}}$. The proof for a decrease in $\mathrm{O}_{3}$ is more fragile, yet there is some recommendation because of the decreases of antecedent transportationrelated poisons. No decreases happened for $\mathrm{PM}_{2.5}$ that could be credited to the SOE.

- China

- China embraced rigid traffic limitations and self-isolate measures, first in Wuhan and neighboring urban communities starting January 23, 2020, and then 2 days after the fact in all areas in China. (Chen et al., 2020) Focused on $\mathrm{NO}_{2}$ and $\mathrm{PM}_{2.5}$ since both are traffic-related air poisons whose discharges were considerably diminished because of the traffic boycotts and home isolate. (Bao \& Zhang, 2020) All things considered, the air quality file (AQI) diminished by $7.80 \%$ and five air poisons i.e., $\mathrm{SO}_{2}$, $\mathrm{PM}_{2.5}, \quad \mathrm{PM}_{10}, \quad \mathrm{NO}_{2}$, and $\mathrm{CO}$ had diminished by $6.76 \%, 5.93 \%, 13.66 \%$, $24.67 \%$, and $4.58 \%$, individually. The lockdowns of 44 cities reduced human movements by $69.85 \%$.

- $\quad$ Egypt

- Egypt took the safety measures of partial and complete lockdown from 15th March till 30th June 2020. Such transient lockdown has significantly affected the decrease of outflows from transportation, mechanical and human exercises. (Abou El-Magd \& Zanaty, 2020) Seen that the air quality over the entire nation is improved because of lessening contaminations discharges, with $\mathrm{NO}_{2}$ diminished by $45.5 \%$, CO outflows diminished by $46.23 \%$, Ozone focus diminished by about $61.1 \%$, and AOD decreased by $68.5 \%$ contrasted with the past 2 years. This exploration utilized multi-information sensors from space to plan the progressions of air quality over Egypt in the initial half-year from January to June 2020 because of the lockdown and contrast and earlier long stretches of 2018 and 2019.

- England

○ The country has applied lockdown in the mid of March, 2020. (Ram \& Morse, 2020) Looked at the 100 days postlockdown (23 March to 30 June 2020) with similar period from the past 7 years. They discovered that nitrogen oxides level the nation over dropped considerably ( $\sim$ half). Notwithstanding, we likewise discover the ozone levels expanded $(\sim 10 \%)$, and the degrees of sulfur-di-oxide dramatically increased the nation over. (Travaglio et al., 2020) They discovered that the degrees of 
certain markers of helpless air quality, nitrogen oxides and ozone, were related with COVID-19 mortality in various English areas, subsequent to changing for populace thickness.

- India

- 21-days nationwide "Curfew/Lockdown announced by the prime minister of India-“Mr. Narendra Modi", to reduce effects and transmission of coronavirus on $25^{\text {th }}$ March. (Sarfraz et al., 2020) Nitrogen Dioxide has vitally decreased up to $30 \%$, and there is a critical improvement in natural quality. Delhi and Mumbai noticed a $40 \%$ to half decrease in Nitrogen Dioxide emanation when contrasted with a year ago. (Singh et al., 2020) The main decrease $\sim 40$ to $\sim 60 \%$ was found in particle matter of $\mathrm{PM}_{2.5}$ and $\mathrm{PM}_{10}$. A considerable reduction $\sim 30$ to $\sim 70 \%$ in $\mathrm{NO}_{2}$ was found. A comparative example was noticed for CO having a $\sim 20 \%$ to $\sim 40 \%$ decrease. Most noteworthy decrease in $\mathrm{PM}_{2.5}$ and $\mathrm{PM}_{10}$ has been assessed for north-west and IGP locales.

- Italy

- After the flare-up of the Coronavirus pandemic in Italy, the public authority has taken uncommon measures, including a public lockdown, to forestall the spread of the disease. (Cameletti, 2020) Po Valley, generally known as one of the most polluted representing about $40 \%$ of the total Italian population areas in Europe in terms of particulate matter (PM) and nitrogen dioxide $\left(\mathrm{NO}_{2}\right)$ concentrations. That paper utilized ITS ARMA models are utilized to survey if the lockdown mediation (legitimate from March 8th, 2020) has prompted a critical decrease in $\mathrm{NO}_{2}$ and $\mathrm{PM}_{10}$ fixations in the city of Po Valley.

- Morocco

- This country was prohibited since the kingdom announced the general lockdown on March 20th, 2020. (Khomsi et al., 2020) Evaluated changes in air quality during verses before the isolate period in 2020 and contrasted these and comparing changes. Air quality data (daily concentrations of $\mathrm{NO}_{2}, \mathrm{PM}_{10}$, and $\mathrm{CO})$ recorded in air quality stations were gathered from the National Weather Service in charge of air quality management in Morocco. Also, showed that COVID-19 lockdown measures have caused a reduction in the concentration levels of the traffic-related pollutants $\left(\mathrm{NO}_{2}, \mathrm{PM}_{2.5}\right.$ and $\left.\mathrm{CO}\right)$ and then the improvement of air quality in the country. Also, and in many other studies, it has been shown that some pollutants such as the ozone $\left(\mathrm{O}_{3}\right)$ may have increased.

- Scotland

- Scotland was extracted for 31-day time period quickly following the implemented of lockdown guidelines on 23 March 2020. (Dobson \& Semple, 2020) $\mathrm{NO}_{2}$ focuses were fundamentally lower in the 2020 lockdown time frame than in the past 3 years. Across Scotland's air pollution monitoring network, observed and normalized $\mathrm{NO}_{2}$ concentrations remained close to constant in 2017, 2018 and 2019 but fell substantially in 2020. These new guidelines prompted considerable falls in street traffic with UK information recommending engine vehicle ventures diminished by around $65 \%$.

- $\quad$ Singapore

- The COVID-19 alert in the country has announced on $7^{\text {th }}$ April. (Li \& Tartarini, 2020) The public degree of every day PSI and mass centralizations of $\mathrm{PM}_{10}$, $\mathrm{PM}_{2.5}, \mathrm{NO}_{2}, \mathrm{CO}, \mathrm{SO}_{2}$, and $\mathrm{O}_{3}$ contrasted and five back to back years (2016-2020). During the lockdown time frame, the public PSI diminished by $19 \%$ contrasted with the anticipated incentive for 2020 . The centralizations of the accompanying contaminations $\mathrm{PM}_{10}, \mathrm{PM}_{2.5}, \mathrm{NO}_{2}, \mathrm{CO}$, and $\mathrm{SO}_{2}$ diminished by $23 \%, 29 \%, 54 \%$, $6 \%$, and $52 \%$, separately, while that of $\mathrm{O}_{3}$ expanded by $18 \%$. The decrease of $29 \%$ in the southern territory of Singapore was the most noteworthy, and $17 \%$ in the west and north was the least. $\mathrm{PM}_{2.5}$ overwhelmed PSI in Singapore, which had the third-most elevated decrease of $29 \%$ broadly.

- Spain

- The Spanish Government had to pronounce a cross country lockdown on the fifteenth of March, considering the quickly spreading infection and high death rate in the country. (Briz-Redón et al., 2020) Shown enhancements for the effect of momentary lockdown during the period from March 15th to April 12th, 2020 on the environmental degrees of $\mathrm{CO}, \mathrm{SO}_{2}, \mathrm{PM}_{10}, \mathrm{O}_{3}$, and $\mathrm{NO}_{2}$ more than 11 agent Spanish urban areas, while the $\mathrm{O}_{3}$ contamination level was found to 
increment. (Mesas-Carrascosa et al., 2020) These results should be taken into account by Spanish governments and policymakers to develop effective $\mathrm{NO}_{2}$ emissions reduction and air pollution prevention policies.

- USA

○ Mr. Donald Trump, president of USA, encouraged residents to restrict travel on 16 March, five days after the World Health Organization proclaimed the COVID-19 episode a worldwide pandemic. (Berman \& Ebisu, 2020) Investigates the continuous effect of the COVID-19 pandemic on estimated U.S. air contamination utilizing the government air checking network. As during COVID-19 pandemic relating to diminished traffic and ordered business terminations. Discoveries present proof that deliberate air contamination has declined across the U.S., $25.5 \%$ decrease in $\mathrm{NO}_{2}$. Diminishes in $\mathrm{NO}_{2}$ are likely connected with decreased vehicular traffic from individuals working distantly and restricted homegrown travel. Percent change of $\mathrm{PM}_{2.5}$ isn't as extensive as that of $\mathrm{NO}_{2}$, and this might be on the grounds that $\mathrm{PM}_{2.5}$ is contributed by numerous non-transportation sources.

\section{CONCLUSION}

Coronavirus is a worldwide pandemic and genuine danger to human wellbeing which stop financial exercises, notwithstanding, it is likewise considered as a "Surprisingly positive development", where contamination is lessening and nature is recovering itself. Lock-down eased back the financial hover on the planet, which brings about the shutdown of creation units and global exchanging. This investigation has assessed the critical impact of lockdown because of COVID-19 on the world's air quality. The paper audits show that the major and minor COVID-19 lockdowns were not long enough to fundamentally improve the air quality with respect to all the broke down toxins. This positive effect on the climate might be brief however governments and people ought to gain from this lockdown on the most proficient method to lessen contamination on a drawn-out premise.

\section{REFERENCES}

1. Abou El-Magd, I., \& Zanaty, N. (2020). Impacts of short-term lockdown during COVID-19 on air quality in Egypt. Egyptian Journal of Remote Sensing and Space Science, $x x x x, 0-7$.

2. Adams, M. D. (2020). Air pollution in Ontario, Canada during the COVID-19 State of
Emergency. Science of the Total Environment, 742, 140516.

3. Anjum, N. . (2020). Good in The Worst: COVID19 Restrictions and Ease in Global Air Pollution. Preprints, April.

4. Balasubramaniam, D., Kanmanipappa, C., Shankarlal, B., \& Saravanan, M. (2020). Assessing the impact of lockdown in US, Italy and France- What are the changes in air quality? Energy Sources, Part A: Recovery, Utilization and Environmental Effects, OO(00), $1-11$.

5. Bao, R., \& Zhang, A. (2020). Does lockdown reduce air pollution? Evidence from 44 cities in northern China. Science of the Total Environment, 731(1954), 139052.

6. Berman, J. D., \& Ebisu, K. (2020). Changes in U.S. air pollution during the COVID-19 pandemic. Science of the Total Environment, 739, 139864.

7. Briz-Redón, Á., Belenguer-Sapiña, C., \& Serrano-Aroca, Á. (2020). Changes in air pollution during COVID-19 lockdown in Spain: A multi-city study. Journal of Environmental Sciences (China), 101, 16-26.

8. Cameletti, M. (2020). The Effect of Corona Virus Lockdown on Air Pollution: Evidence from the City of Brescia in Lombardia Region (Italy). Atmospheric Environment, 239(July), 117794.

9. Chang, H.-H., Meyerhoefer, C., \& Yang, F.-A. (2020). COVID-19 Prevention and Air Pollution in the Absence of a Lockdown. National Bureau of Economic Research.

10. Chen, K., Wang, M., Huang, C., Kinney, P. L., \& Anastas, P. T. (2020). Air pollution reduction and mortality benefit during the COVID-19 outbreak in China. The Lancet Planetary Health, 4(6), e210-e212.

11. Coker, E. S., Cavalli, L., Fabrizi, E., Guastella, G., Lippo, E., Parisi, M. L., Pontarollo, N., Rizzati, M., Varacca, A., \& Vergalli, S. (2020). The Effects of Air Pollution on COVID-19 Related Mortality in Northern Italy. Environmental and Resource Economics, 76(4), 611-634.

12. Contini, D., \& Costabile, F. (2020). Does air pollution influence COVID-19 outbreaks? Atmosphere, 11(4), 377.

13. Dobson, R., \& Semple, S. (2020). Changes in outdoor air pollution due to COVID-19 lockdowns differ by pollutant: Evidence from Scotland. Occupational and Environmental Medicine, 77(11), 798-800.

14. Fu, F., Purvis-Roberts, K. L., \& Williams, B. (2020). Impact of the covid-19 pandemic lockdown on air pollution in 20 major cities around the world. Atmosphere, 11(11).

15. Gautam, S. (2020). The Influence of COVID-19 on Air Quality in India: A Boon or Inutile. Bulletin of Environmental Contamination and Toxicology, 104(6), 724-726.

16. Ghahremanloo, M., Lops, Y., Choi, Y., \& Mousavinezhad, S. (2020). Impact of the 
COVID-19 outbreak on air pollution levels in East Asia. Science of the Total Environment, $754,142226$.

17. Helen A (2020) The Ultimate Guide to Understanding Air Quality Data in 2020. Breez Meter, 2 Jan. 2020, accessed on 31 March 2020.

18. Hoang, T., \& Tran, T. T. A. (2020). Ambient air pollution, meteorology, and COVID-19 infection in Korea. Journal of Medical Virology, June, 18.

19. Huang, G., \& Brown, P. E. (2020). Populationweighted exposure to air pollution and COVID19 incidence in Germany. Spatial Statistics, 41, 100480.

20. Islam, M. S., Tusher, T. R., Roy, S., \& Rahman, M. (2020). Impacts of nationwide lockdown due to COVID-19 outbreak on air quality in Bangladesh: a spatiotemporal analysis. Air Quality, Atmosphere and Health, June.

21. Khomsi, K., Najmi, H., Amghar, H., Chelhaoui, Y., \& Souhaili, Z. (2020). COVID-19 national lockdown in morocco: Impacts on air quality and public health. One Health, 11, 100200.

22. Li, J., \& Tartarini, F. (2020). Changes in air quality during the COVID-19 lockdown in singapore and associations with human mobility trends. Aerosol and Air Quality Research, 20(8), 1748-1758.

23. Mesas-Carrascosa, F. J., Porras, F. P., TriviñoTarradas, P., García-Ferrer, A., \& MeroñoLarriva, J. E. (2020). Effect of lockdown measures on atmospheric nitrogen dioxide during SARS-CoV-2 in Spain. Remote Sensing, 12(14).

24. Muhammad, S., Long, X., \& Salman, M. (2020). COVID-19 pandemic and environmental pollution: A blessing in disguise? Science of the Total Environment, 728, 138820.

25. Ram, C. A., \& Morse, M. A. G. A. P. (2020). Higham2020AQAH

COVID19Lockdown100DaysOfAirUK.pdf.

26. Rossi, R., Ceccato, R., \& Gastaldi, M. (2020). E ff ect of Road Tra ffi $c$ on Air Pollution . Experimental Evidence from COVID-19 Lockdown. 2, 14-17.

27. Sarfraz, M., Shehzad, K., \& Shah, S. G. M. (2020). The impact of COVID-19 as a necessary evil on air pollution in India during the lockdown. Environmental Pollution, 266, 115080.

28. Singh, V., Singh, S., Biswal, A., Kesarkar, A. P., Mor, S., \& Ravindra, K. (2020). Diurnal and temporal changes in air pollution during COVID-19 strict lockdown over different regions of India. Environmental Pollution, 266, 115368.

29. Son, J. Y., Fong, K. C., Heo, S., Kim, H., Lim, C. C., \& Bell, M. L. (2020). Reductions in mortality resulting from reduced air pollution levels due to COVID-19 mitigation measures. Science of the Total Environment, 744, 141012.

30. Travaglio, M., Yu, Y., Popovic, R., Selley, L., Leal, N. S., \& Martins, L. M. (2020). Links between air pollution and COVID-19 in England. Environmental Pollution, 268.

31. Venter, Z. S., Aunan, K., Chowdhury, S., \& Lelieveld, J. (2020). Air pollution declines during COVID-19 lockdowns mitigate the global health burden. Environmental Research, November, 110403. 